\title{
Introducing Engineering Students to Historical/Cultural Perspectives through Story-Centered on-Line Learning
}

\author{
Luis A. Godoy \\ Department of Civil Engineering and Surveying, University of Puerto Rico at Mayaguez, Mayaguez, \\ Puerto Rico. \\ Email: luis.godoy@upr.edu \\ Received March 25 ${ }^{\text {th }}$, 2011; revised April 18 ${ }^{\text {th }}, 2011$; accepted May $5^{\text {th }}, 2011$.
}

\begin{abstract}
Several authors argued that history of science should be an integral part of science education; however, there are many obstacles to carry out an implementation within this approach, including that lecturers normally lack a necessary historical background (a situation that is largely aggravated in engineering faculties), and the impossibility of including new courses or credits in an already tight curriculum. The development of on-line modules that engineering students can work outside their normal schedule of classes, introducing historical/cultural perspectives, is presented in this paper. E-learning and knowledge management strategies are used in the context of science education at undergraduate and graduate levels. The approach is based on learning-by-doing in a virtual environment, and specifically presents story-centered activities, in which the student is faced with a problem and plays the role of an expert to provide a solution to the case. The specific case considered develops in the form of a controversy concerning the origin of the studies of column buckling. Two sets of information are available for navigation in the module: specific information that the student can explore (containing historical material directly connected to the case provided), and more general information (providing the historical/cultural context to the problem). A first application has been made with civil engineering students, who had to write a two-page white paper as a consequence of their work on the problem. The interest generated in the participating students and the positive evaluation of their experience seems to indicate that this type of activity can serve to enhance traditional engineering lectures by incorporating a historical dimension. The present web-based approach could be extended to tackle similar conflicts in fields for which there is ample documentation available in the literature or in other historical episodes which may lead to rich discussions.
\end{abstract}

Keywords: E-Learning, Engineering Education, Historical Approach, Science Teaching

\section{Introduction}

The need to include history of science as an important part of science education has been argued by Klopfer (1969a, 1969b), Herget (1989), and Matthews (1994), among others, during the last 40 years. The reasons behind such claim are similar to those that may be found in support of the study of history of science itself, as exposed by Kragh (1987). Although the role of history of science in science teaching has been mainly considered for high school education, its role in engineering education should also be emphasized. Current American and European accreditation standards state that historical and cultural perspectives should be part of the education of every engineer.

The study of history and evolution of concepts as part of learning a discipline is important to provide a historical dimension to education; otherwise students tend to believe that the concepts and methods that they use are the product of just the last few years of research. This time dimension is also crucial to locate their own work as part of an old tradition. There are other reasons why the history of a discipline should be part of the way we teach. An examination of the order in which structural topics are taught in engineering courses (statics/ strength of materials or mechanics of materials/structural analysis/elasticity) illustrates that we follow the sequence in which those topics were investigated in the history of the discipline.

In supporting a historical perspective, Kopfler (1969a) states that teaching a historical episode requires information on the considered topic; understanding concepts and principles as they were understood in the period considered; and a framework regarding science and scientists during those times.

Several techniques have been used to introduce historical perspectives, such as lectures, reproduction of early experiments, dramatization, role playing, readings of original texts, and others. However, the main limitation seems to be the lack of historical background of lecturers in charge of a course. Thus, the possibility of having modules with a historical perspective, which may be directly used by students with little or no advice from their local lecturer, becomes attractive.

This paper reports on the development of a module within the context of teaching buckling phenomenon to engineering students. Most engineering students are taught about "Euler buckling load" in Mechanics of Materials, Strength of Materials (at undergraduate level), and Theory of Elastic Stability (at graduate level) courses. The developed module is based on historical research done by the author (Godoy, 2007, 2010) and others, including Timoshenko (1953), Truesdell (1968), Benvenutto (1991), Heyman (1998).

\section{Learning-by-Doing in a Web-Based Environment}

The efficacy of student active learning has been investigated 
by a number of researchers, and reviews may be found in compilations by Prince (2004) and by Froyd (2007). Prince found evidence that supports most forms of active learning. He concluded that different implementations of problem-based learning emphasize different elements and this makes it difficult to state a general assessment of this approach; however, it seems that this "positively influences students attitudes and students habits. Studies also suggest that students will retain information longer and perhaps develop enhanced critical thinking and problem-solving skills" (Prince, 2004).

Basically, the strategy of learning-by-doing supports that students learn by performing activities aimed at reaching a pre-established goal, and not (only) by listening to an instructor in a lecture. Advocates of learning-by-doing stress the role of doing as part of preparing to perform in a profession. According to Schön (1987), the main features of reflection in action are learning by doing, coaching rather than teaching, and creating a dialogue between coach and student. Effective forms of learning by doing in real laboratories have been implemented in Engineering Education, especially for capstone courses. Alternatively, a methodology of building a simulated scenario, in which the student can learn-by-doing while interacting with fictitious characters (some of whom provide coaching), has been proposed by Schank (2002) as an effective form of active learning. Most simulations described by Schank and co-workers deal with training to perform managerial tasks. A review on the potential relevance of this approach as part of the education of engineers has been recently presented by the author (Godoy, 2009).

In the early tools developed by Schank and coworkers, simulations as close to reality as possible were developed, involving animations and multimedia; however, the cost of such implementations may become prohibitive if a realistic simulation is attempted (Schank, 2005). An alternative has been proposed in the form of Story-Centered Activities (SCA), which are also forms of active learning in a computer environment (Schank \& Cleary, 1995). In SCA the participant performs tasks to reach a goal; however, SCA do not attempt to create fictitious characters or realistic situations to represent real life. As an example, Schank and Cleary describe a master's course in which a mission is given to the student through an e-mail from a fictitious character (Schank \& Cleary, 1995). This communication includes details of what should be the outcome of the work to be performed as a consequence of the research. In this example there is no navigation dimension (which is the most expensive part to implement in simulations). To help students do their work, guidelines and reading materials are provided for download from internet sites. The guidelines provided list the activities that should be completed in each case to achieve something. Examples of step-by-step guides may include: "Read through the analysis objectives and evaluation requirements listed in the e-mail; Download the template for the analysis and recommendation report; Download and read through the case material on the case"; etc. The final report submitted by students should respond to specific questions, which include an analysis of a situation and recommendations about how one should proceed next. This form of active learning does not employ videos or recordings and is far simpler to implement than a more realistic simulation. The evaluation of the report produced by the participant is made in an asynchro- nous mode. In broad terms, this may fall in the category of problem-based learning, in which a significant problem is posed to the students in order to provide motivation for learning.

The educational model for this initiative falls within what is known as a constructivist approach. There is not just one constructivist theory, but there is a group of researchers in education who share some fundaments about how a student learns (Duschl \& Hamilton, 1992, Ashman \& Conway, 1997). The main references in this field are based on the works of Jean Piaget (1972, 1974) and Lev Vygotsky (1931/1997a, 1931/ 1997b), which have been extensively employed in the USA (Bransford, Brown, \& Cocking, 1999).

The basic assumptions of constructivist theory, which are accepted in this work, may be written as follows: 1) Knowledge is a construction of the person. Thus, it is not conceived as something that a teacher can transfer directly to a student because the teacher has knowledge and can give it to the students. In the constructivist approach there should be an involvement and participation of the student. 2) This construction is an active process. The student will make meaningful learning by means of activities. The present project is centered on activities carried out by the student in the simulated environment. 3) This activity of the student takes place in a context of cooperation with others. This cooperation could be implemented in a computer environment through the forum and chat rooms; however, this has not been implemented at present. 4) The learning activity is done within a historical and cultural context. Learning changes as a consequence of the existence of cultural artifacts available during the process. The cultural artifacts in this project are the computer simulations, which are part of present day technology of education. The first three premises are shared by both Piaget and Vygotsky, but the fourth is the new aspect considered in the works of Vygotsky.

\section{Design of the Story}

The activity has been designed following the work of Kieran Egan on the use of storytelling as part of teaching. Egan (1986) proposed a model for planning a teaching activity and organized it around a story. To facilitate construction of the story, Egan presented five activities and questions for each one of them. This scheme has been followed by the author in designing the present activity, and the approach is given next:

1) Identifying importance: What is most important about this topic? Why should it matter to students? What is affectively engaging about it? Buckling is usually considered as a mystifying phenomenon, an unexpected sudden failure of a structure. Buckling problems are included in most engineering programs, with differences in emphasis depending on the branch of engineering considered and on the instructor's preferences. It is part of "Mechanics of Materials" in sophomore courses, and in graduate structural courses. Thus, adding a historical dimension to this topic may have a larger impact than other more specialized topics that are not always covered. It should be clear to students that column buckling problems have been faced by engineers for over two centuries as a matter of survival of wood constructions. The discovery of buckling phenomenon should be seen as a truly amazing achievement: Scientists in the XVII Century had no understanding of buckling problems. 
In the first section of the paper we discussed arguments in support of the introduction of a historical perspective in science and engineering courses. However, it does not follow that students have a clear idea of the benefits that this perspective may bring to them. Preliminary interviews conducted with the group of students at the University of Puerto Rico who later participated in the on-line activity, show that they believe that it would be good to have some historical background but cannot identify reasons in support of a historical perspective.

Students find that an activity is engaging whenever they have to do something as part of that activity. Doing is usually more engaging when they construct at least part of the knowledge that they use.

2) Finding binary opposites: What powerful binary opposites best catch the importance of the topic? As stated by Egan, in every story there is usually more than just one set of binary opposites. In terms of historical characters, an excellent pair is Petrus van Musschenbroek (PvM) and Leonhard Euler, who both addressed buckling problems in the XVIII Century from quite different perspectives and backgrounds. At another level, there is an opposition between different ways of arriving at knowledge: The experimental versus the mathematical way. This also means a conflict between the more traditional XVIII Century experimentalists (such as PvM) and the "modern" theoreticians or geometers (such as Euler). Those binary opposites are central to the development of the present teaching module.

3) Organizing contents into story form: What content most dramatically embodies the binary opposites, in order to provide access to the topic? What content best articulates the topic into a developing story form? The opposition of the two historical characters regarding who was the pioneer of buckling studies has the necessary tension as to generate a conflict and a story. The search for the origins of a discipline requires an inquiry into who contributed what and when. A key content that dramatizes the binary opposites to present day viewers is a consideration of primacy in an important discovery, such as the buckling of columns.

The chosen topic (origins of buckling studies) and the activities carried out by students (discovering the level of understanding in each author) can be articulated in a story in which context and circumstances take part and are required ingredients.

4) Story conclusion: What is the best way of resolving the dramatic conflict inherent in the binary opposites? What degree of mediation of those opposites is it appropriate to seek? Closing the story should be done by the student, not by the designer of the activity. This conflict can only be solved by assessing the available evidence, including a time line (dating discoveries), and a comparison of how each author addressed the phenomenon. Use should be made of the fact that PvM identified the buckling problem and searched for a predictive model via experiments, whereas Euler used a theory and found a problem that needed an explanation. For a long time, Euler did not understand the phenomenon that was behind the equations.

Although PvM was the first to investigate the phenomenon and identify the controlling parameters, he did not have a theory under which this behavior could fit. Euler, on the other hand, had a theory but this could not be clearly identified with reality. Some historians of science believe that an intermediate
"Euler-Musschenbroek buckling load” identification should be made to acknowledge both contributors. This story provides the possibility that the student discovers such gray aspects in the historical reconstruction.

5) Evaluation: How can one know whether the topic has been understood, its importance grasped, and the contents learned? To verify that learning has occurred, the written production of the student should be considered. A two-page white paper is a sufficiently short piece of writing so that it can be completed in a limited time (say two hours), and at the same time should contain substantial understanding in order to convince an impartial reader about who should be considered as the father of buckling studies.

This story telling exercise provides a good planning base for the teaching activity, and the next stage is the translation of all that into an on-line module.

\section{On-Line Learning Module}

This section describes details of a computer-based learning tool developed by the author to introduce a historical dimension in an engineering (advanced undergraduate/graduate) course. The activities reported in this paper are performed by students in a computer-simulated environment, in which they are assigned a role and follow a mission. This strategy has been previously employed by the author to teach structural failures to engineering students (Godoy, 2009b, 2010b). The reader can access the present module in Internet at (Godoy, 2010c).

In the opening page (Problem statement, see Figure 1) the participant finds a communication from a credible fictitious character, the secretary of an "Institute for the Understanding of Mechanics from a Historical Perspective”. The participant

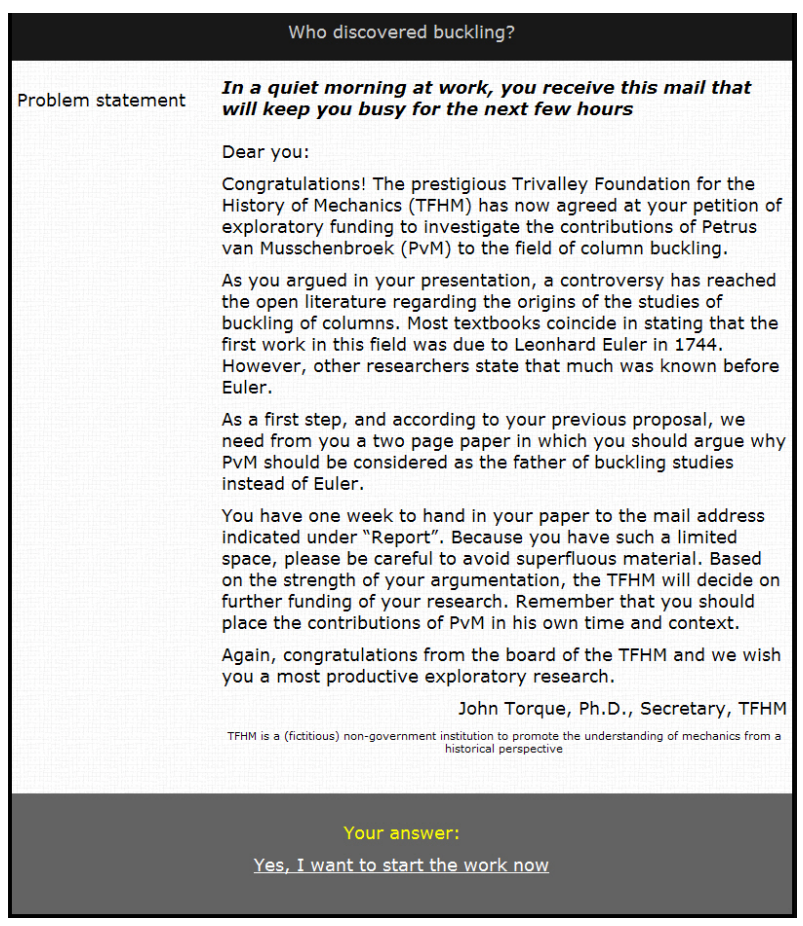

Figure 1.

Module screen with problem statement. 
learns that he/she has been awarded an exploratory grant to investigate the contributions of Petrus van Musschenbroek $(\mathrm{PvM})$ to the field of column buckling. The participant is now requested to write a two-page white paper to argue why PvM should be considered the father of buckling studies instead of Euler. Graduate student survival often depends on grants, so they know that even the fictitious possibility of a grant being awarded to them has to be considered with care.

The site contains a large amount of information regarding the specific scientists considered and the context in which PvM lived and worked. The information that is specific to the case is organized in the form of a decision tree, as schematized in Table 1 and Figure 2. The information that provides a context to the case is organized as in Table 2 and Figure 3, under the label "Ask the experts". There is a library with a list of publications, including books and papers on the Musschenbroek, and books on the history of structural mechanics. Finally, specific instructions on the white paper that the participant should write are provided under "Report", as shown in Figure 4.

Two experts reviewed the module, one with a background in information and telecommunication technologies, whereas another expert reviewed the engineering contents. The contents expert noticed that not enough information had been included on the contributions of Euler, with the consequence that it was difficult to assess the relative merits of PvM. The technologies expert suggested the use of visual images to illustrate cultural aspects of Holland at the time when PvM lived there. As a consequence of those reviews, sections on "Holland in the XVII and XVIII Centuries" and "What did Leonhard Euler write on compressed columns?” were added.

\section{Evaluation of Student's Performance}

A group of 23 students participated in this activity during 2010, as part of a Master's course at the University of Puerto Rico. The navigation took approximately 2.5 hours, whereas

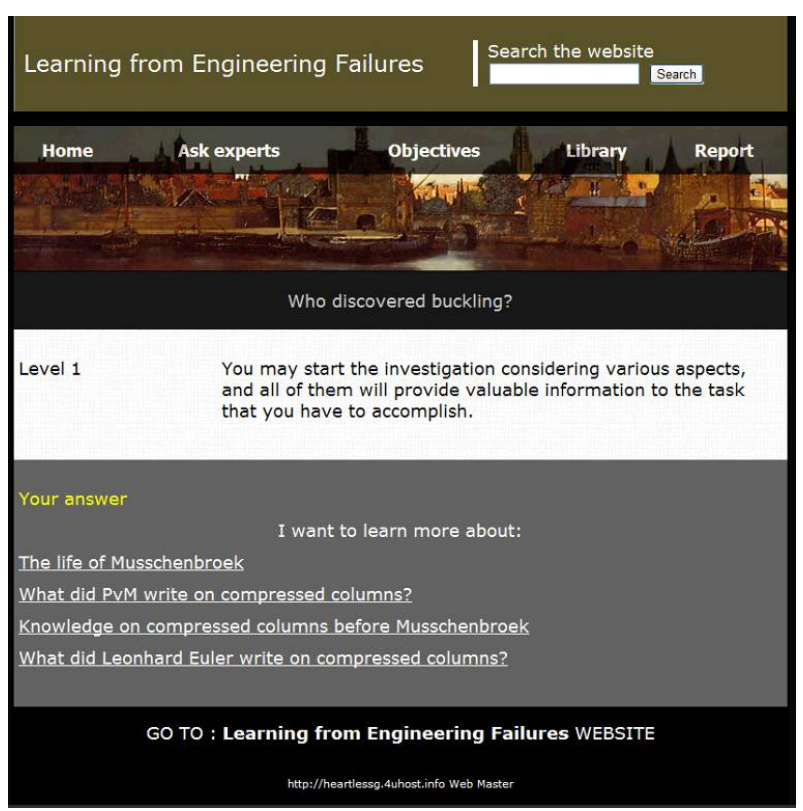

Figure 2.

Navigation through the case.

Table 1.

Organization of the navigation tree in the module.

PvM in early and present day encyclopedias

Who was PvM?

...the life of PvM

...what PvM wrote on compressed columns

I need to learn more about..
Why his family should be considered in any account of PvM?

The fabrication of scientific instruments in Holland and Europe

I want to learn about the 1729 version of compressed columns

I want to learn about the 1762 version of compressed columns

What was the impact of the work of PvM?

Show me the list of all books published by PvM

How old is the concept of stability?

Why more structures did not fail due to buckling in ancient and medieval times?

What did Leonardo contribute to this topic?

What did Merssene contribute to this topic?

What did Euler contribute to this topic?
Show me pictures of PvM

Leonardo in Wikipedia

Merssene in Wikipedia

Euler in Wikipedia 
Table 2.

Organization of expert advice in the module.

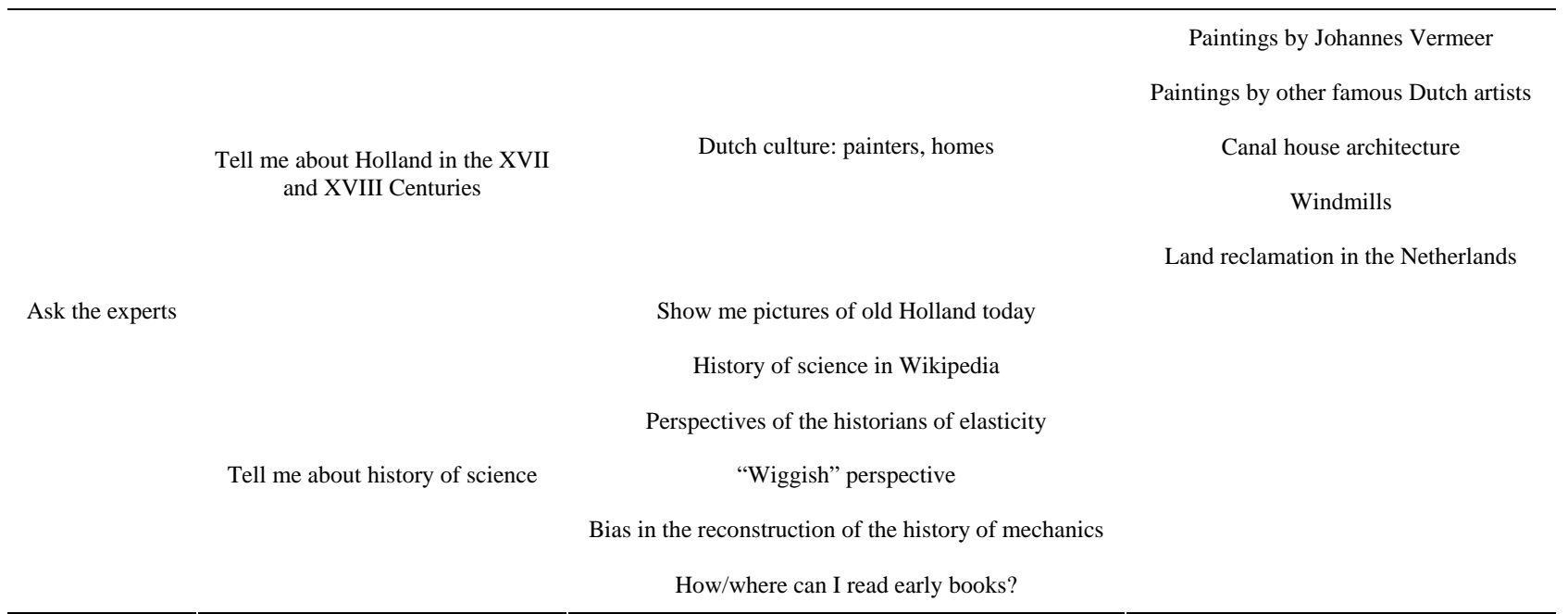

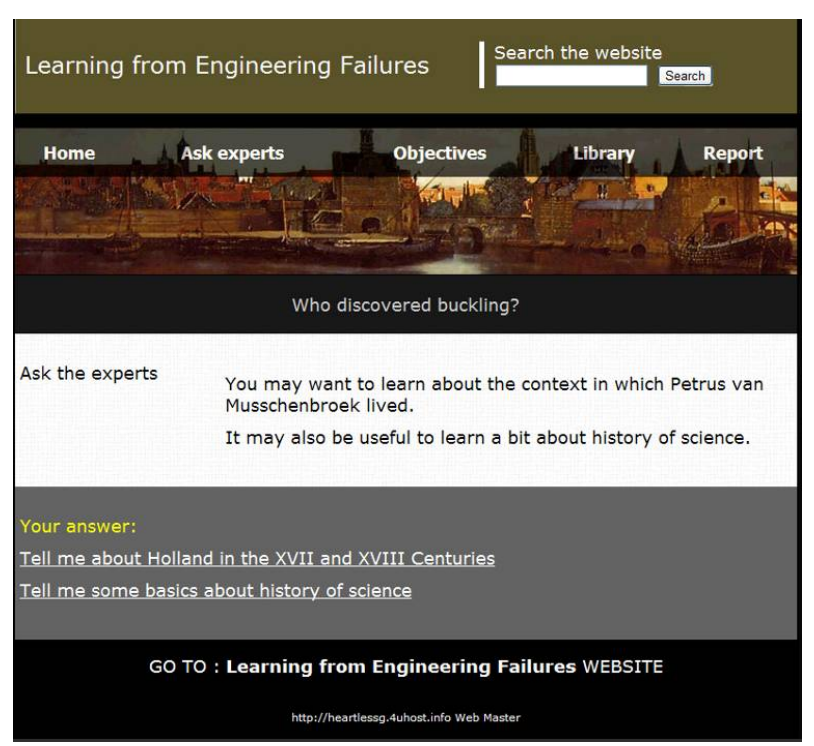

Figure 3.

Asking the experts screen.

writing the white paper took them another 2.5 hours.

Assessment Prior to the Intervention: Pre-tests were not administered in this case but in-depth interviews were conducted with each student to learn about their background and perspectives in relation with the proposed intervention. The results of the interviews were fairly consistent: 1 ) Students knew the name of Euler and acknowledged that he must have written the buckling formula that has his name, but could not identify in what century Euler lived. 2) Students could not identify benefits for studying the history of buckling or any other topic in mechanics, except that it may be interesting to learn something different for a change. 3) Students had the impression that the contents that they study in engineering are the outcomes of recent research. 4) Most students had taken a Humanities course at undergraduate level, however, they did not know that Holland was an important power in Europe for a long period in

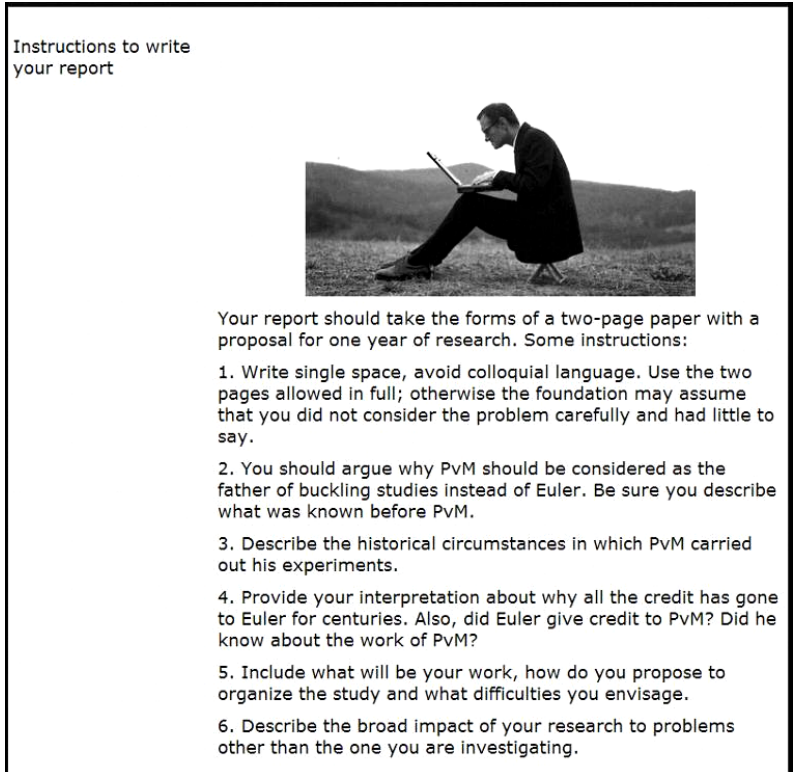

Figure 4.

Screen containing instructions to write the white paper.

history.

Assessment of learning: The evaluation of the performance of students was based on the two page white paper that they wrote to complete the activity. The main question here is: Has the story of PvM and Euler refined further their understanding of the complexities behind science/engineering history? As stated by Egan, degrees of refinement of understanding are difficult to measure.

A check-list (in the form of questions listed in Table 3) was prepared to verify if the students addressed the topics that they were expected to discuss. The first ten questions correspond to argumentation about the case, and the last five questions considered the proposal for future work. A qualitative evaluation of the white paper was carried out, to consider the level of know- 
Table 3.

Questions used for the evaluation of the white paper.

\begin{tabular}{|c|c|c|c|c|}
\hline Did the student... & A & B & C & D \\
\hline $\begin{array}{l}\text {... state the problem being addressed? } \\
\ldots \text { explain the phenomenon under consideration? } \\
\ldots \text { describe what was known before PvM? } \\
\ldots \text { include a summary of PvM life and achievements? } \\
\ldots \text { summarize the work of PvM on buckling? } \\
\ldots \text { summarize the work of Euler on buckling? } \\
\ldots \text { comment on why Euler did not give credit to PvM? } \\
\ldots \text { interpret why all credit has gone to Euler for centuries? } \\
\ldots \text { argue why PvM should be considered the father of buckling studies? } \\
\ldots \text { identify the context in which PvM and Euler worked? }\end{array}$ & & & & \\
\hline $\begin{array}{l}\text {... write a proposal for a one year research? } \\
\text {... include what will be the work? } \\
\ldots \text { propose how the study will be organized? } \\
\text {... identify difficulties in performing the study? } \\
\text {.. describe the broad impact of the research? }\end{array}$ & & & & \\
\hline
\end{tabular}

ledge and the quality of the argumentation for each question. Each question was rated as A, B, C (in the form of grades usually assigned in evaluations), and D if the topic had not been addressed by the student. This instrument allowed establishing differences in the quality of the responses.

Assessment after the Intervention: A post-test was administered in order to identify student's perceptions after the activity. The post-test contained a number of statements and the students had to answer using a Likert scale containing three possibilities of agreement.

Some statements in the post-test attempted to identify reasons why investigating the history of a discipline may be important, such as

- The early sources of research in a scientific discipline are important because they allow..

- $\quad$... reconstructing the history of the discipline.

- ... identifying the context in which the ideas developed.

In contrast, other questions addressed the idea that history is not relevant because we only use current ideas (contents) and practices (methodologies):

- The history of a discipline is not relevant today because...

- ... we now use the most up-to-date versions of all knowledge.

- $\quad$... the methods we now use to arrive at new knowledge is different from how it was done say 200 years ago.

The importance of the historic/cultural context is considered in two statements: In a general statement the importance of the context is highlighted, whereas in a specific statement it is diminished.

- It is crucial to understand the historical/cultural context in which a researcher works to reconstruct his/her contributions to science.

- PvM lived in Holland at a time in which the country was one of the main European powers, but he could have made his discoveries in any other country.

Regarding how important the fame and recognition of a scientist are in attributing to him/her the priority of a discovery, there were two statements:
- Euler was considered the pioneer in buckling studies because of his fame.

- The prestige of a scientist is crucial in the evaluation of his/her discoveries.

Other statements addressed the historiography of science

- The facts in the history of science do not speak by themselves and it is necessary to write argumentation about them.

- The errors made in the history of science are always corrected in a short time because the available evidence allows clearing all doubts.

The questions were not paired as they have been done here for the discussion, but were mixed in a random way.

Because the student population that used this module was small, results are not presented here, but they showed a clear improvement in student's perspectives with respect to pre-intervention interviews.

\section{Student Evaluation of the Activity}

To evaluate the effectiveness of the learning module, the students answered five open questions with their opinions of the activity. In general terms, it may be said that students greatly enjoyed this activity. The two most relevant questions are discussed next:

Do you consider that you learned as in a standard lecture, more than in a standard lecture, or less? All students responded that they learned more than in a standard lecture, and their reasons were:

- "Because I had the opportunity to investigate a topic, which is not possible to do in a normal class due to time constraints."

- "Because we learned different things: in a normal lecture, learning focuses on the understanding and application of the concepts, but here we learned about how those concepts were developed."

- "What I learned here I will remember, I will fix it much better thanks to the activity." 
- "The nature of the material was not so difficult to understand, so that we could learn it by ourselves."

- "I think that the learning material was very interesting and motivated us to continue doing research without any limitations.”

- "In historical topics, in which there is argumentation and bibliographical research, we learn much more than in a normal class because the student constructs his own knowledge about a topic."

- "Because the time dedicated to study was more than in a standard lecture."

Students valued several aspects of this activity and identified its strengths and weaknesses:

- "It helped us to improve searching, argumentation and writing skills."

- "It provided a historical background to the course that we take.”

- "Thanks to this activity, we studied in detail the context of a discovery, and the main aspects about how it developed (historic context, society and historic times)."

- "It was a change with respect to other activities carried out in the course."

- "For the first time, we had to consider historical and cultural aspects in engineering."

- "Knowledge was acquired at a deep level, because we arrived at that knowledge by ourselves."

- "Most graduate students should be interested in learning how the knowledge that is used at present was discovered in the past."

- "We do not have experience in writing proposals and this activity was helpful to identify the components and format of a proposal, even a short one like the white paper required."

- "The activity was appropriate for the kind of topics discussed in it, but may be less effective for other topics that require heavy use of equations.”

- "I found little information in Internet about PvM and his buckling experiments, but there was much more available about Euler."

- "Not every topic in a course can be taught using this methodology because of the time it requires to complete the work."

- "It takes time and concentration to organize our ideas and write them in a coherent document."

\section{Conclusion}

This paper illustrates the development and application of an on-line module to learn historical perspectives in relation to an engineering topic. The module is highly interactive, allowing the student to navigate the on-line module to learn with a purpose in mind, which is provided by the mission that needs to be accomplished.

Some preliminary conclusions may be drawn at this stage:

- An on-line tool, such as the one discussed in this paper, may be employed in class as a self-contained tool, without the need to consult a local teacher or a real expert.

- Students usually view history as dominated by battles, kingdoms and power. But here they are able to see that history is also hidden behind the engineering achievements of the past: there is a hidden history in their engineering discipline, not only in the history books and museums.

- Students enjoy working in this form and consider that they learned more than in a traditional lecture. The reasons why they learn more are because they had to apply the concepts immediately; and they were active investigators instead of passive listeners.

- Learning retention may increase because students can associate knowledge to a story instead of keeping knowledge in the vacuum.

- Students enjoy that they can "construct" knowledge "by doing research".

- Students appreciated having an activity that is completely different than traditional lectures.

- Students believe that the effectiveness of the activity is related to its contents being "soft", but are not convinced that this technique may work well for more technical contents that are full of equations.

Future work in this field includes employing this on-line module with a group of undergraduate students during the next two years; this, however, is outside the scope of this paper.

\section{Acknowledgements}

This work was possible thanks to the support of NSF-CCLI grant DUE-0736828: “A Computer-Based Simulated Environment to Learn on Structural Failures in Engineering” (Program Director: Ann McKenna). However, the results and opinions expressed are solely those of the authors and do not necessarily reflect the views of the funding agency. The author thanks the contribution of graduate student Jean Batista-Abreu in the implementation of the on-line tool.

\section{References}

Ashman, A. F., \& Conway, R. N. F. (1997). An introduction to cognitive education. London: Routledge.

Benvenutto, E. (1991). An introduction to the history of structural mechanics. New York: Springer-Verlag.

Bransford, J. D., Brown, A. L., \& Cocking, R. D. (1999). How people learn: Brain, mind, experience and school. Washington, DC: National Research Council.

Duschl, R. A., \& Hamilton, R. J. (1992). Philosophy of science, cognitive psychology, and educational theory and practice, New York, NY: State University of New York Press.

Egan, K. (1986). Teaching as story-telling. Chicago, IL: The University of Chicago Press.

Froyd, J. E. (2007). Evidence for the Efficacy of Student-Active Learning Pedagogies. PKAL (Project Kaleidoscope), URL (last checked 15 March 2011).

http://www.pkal.org/documents/BibliographyofSALPedagogies.cfm

Godoy, L. A. (2006). Historical sense in the historians of the theory of elasticity. Meccanica, 41, 529-538. doi:10.1007/s11012-006-9001-2

Godoy, L. A. (2009a). Developing a computer-based simulated environment to learn on structural failures. In Proceedings of the ASEE annual conference. Austin.

Godoy, L. A. (2009b). Una revisión del programa de investigación sobre aprendizaje activo en un ambiente simulado desde la perspectiva de la educación en Ingeniería. Latin American and Caribbean Journal of Engineering Education, 3, 61-75.

Godoy, L. A. (2010a). Estabilidad de estructuras: Una perspectiva histórica. Barcelona: CIMNE. 
Godoy, L. A. (2010b). Story-centered learning in a computer simulated environment. Proceedings of the ASEE Annual Conference. Louisville, KY.

Godoy, L. A. (2010c). Who Discovered Buckling? http://lef.uprm.edu/Historical\%20investigation/index.html.

Herget, D. E. (Ed.) (1989). The history and philosophy of science and science teaching. Talahasee, FL: Florida State University.

Heyman, J. (1998). Structural analysis: A historical perspective. Cambridge: Cambridge University Press.

Klopfer, L. E. (1969a). Case histories and science education. San Francisco, CA: Wadsworth.

Klopfer, L. E. (1969b). The teaching of science and the history of science. Journal of Research in Science Teaching, 6, 87-95. doi:10.1002/tea.3660060116

Kragh, H. (1987). An introduction to the historiography of science. Cambridge: Cambridge University Press. doi:10.1017/CBO9780511622434

Matthews, M. R. (1994). Science teaching: The role of history and philosophy of science. New York: Routledge.

Piaget, J. (1972). Principles of genetic epistemology. New York: Basic Books.

Piaget, J. (1974). Biology and knowledge. Chicago, IL: The University of Chicago Press.

Prince, M. (2004). Does active learning work? A review of the research. ASEE Journal of Engineering Education, 93, 223-231.

Schank, R. C. (2002). Designing world class E-learning. New York: McGraw-Hill.

Schank, R. C. (2005). Lessons in learning, e-learning, and training. New York: Pfeiffer (Wiley)

Schank, R. C., \& Cleary, C. (1995). Engines for education. Hillsdale, NJ: Lawrence Erlbaum.

Schön, D. (1987). Educating the reflective practitioner. New York: Jossey-Bass Publications (Wiley).

Timoshenko, S. (1953). History of strength of materials. New York: McGraw-Hill.

Truesdell, C. A. (1968). Essays in the history of mechanics. Berlin: Springer-Verlag.

Vygotsky, L. S. (1931/1997b). Problems of general psychology. In R. W. Riber, \& A. S. Carton (Eds.), The collected works of LS Vygotsky, 1. New York: Plenum Press.

Vygotsky, L. S. (1931/1997a). The history of the development of higher mental functions, In R. W. Riber (Ed.), The collected works of LS Vygotsky, 4. New York: Plenum Press. 